\title{
On the Chinese Dream from Practical Wisdom
}

\author{
ZHANG Jun ${ }^{1} \&$ WEI Qing ${ }^{2}$ \\ ${ }^{1}$ Shaoxing University, China; ${ }^{2}$ Zhejiang Yuexiu University, China \\ Received: July 20, 2021 \\ Accepted: August 16, 2021 \\ Published: November 30, 2021
}

To cite this article: ZHANG Jun \& WEI Qing. (2021). On the Chinese Dream from Practical Wisdom. Asia-Pacific Journal of Humanities and Social Sciences, 01: 3, 072-076, DOI: 10.53789/j.1653-0465.2021.0103.008.p

To link to this article: https://doi.org/10.53789/ j.1653-0465.2021.0103.008.p

The research project is supported by Shao Xing Planning Project of Philosophy and Social Science (145S004) and the School Scientific Project of Shaoxing University entitled "The History and Present Situation of Marxism as a Scientific Philosophy Abroad" with NO. 2020SK001; and by the Start-up Project of Shaoxing University entitled "The Study of Marxism as a scientific philosophy Abroad" with NO. 20206011.

\begin{abstract}
The Chinese Dream is the rational pursuit of China's social development, the overall perception, discrimination, and insight of the current Chinese social situation, and the manifestation of the Chinese spirit. Targeting the realization of all-around personal development and the construction of a harmonious society, the "Chinese Dream" integrates theoretical and practical rationality, embodies the unity of illustrating the world and changing the world, and is the unity of practice and wisdom. Based on Aristotle's practical wisdom, the interpretation of the scientific connotation of the "Chinese Dream" will help us understand the theoretical purport of the "Chinese Dream" from its source and essence, which is of great significance for strengthening the socialist construction and promoting the construction of a harmonious society in the new era.
\end{abstract}

Keywords: Chinese Dream; practical wisdom; Chinese spirit

Notes on the contributors: Zhang Jun, holds a doctoral degree from East China Normal University. He works at Shaoxing University, and his academic interest lies in Marxism in China. Wei Qing holds a master's degree from Shandong Agricultural University. She works at Zhejiang Yuexiu University, and her academic interest lies in foreign language teaching and ideological and political courses.

\section{論“中國夢”的實踐智慧 \\ 張 軍 ${ }^{1}$ 魏 清 $^{2}$ \\ ${ }^{1}$ 紹興文理學院; ${ }^{2}$ 浙江越秀外國語學院}

摘 要: “中國莺” 是對中國社會發展的合理性追求, 對當下中國社會情景的整體感知、辨別與頓 
悟, 對中國精神的彰顯。以實現個人全面發展和構建和諧社會為指向的 “中國蓦”, 融合了理論理 性與實践理性, 體現了描述世界和改變世界的統一, 是實踐與智慧的統一。立足于實践智慧, 解讀 “中國营” 的科學內涵, 有助於從根源和本質上認清 “中國夢” 的理論旨趣, 對於加強新時期社會主 義建設和促進和諧社會構建具有重要意義。

關鍵詞: 中國蓦; 實踐智慧; 中國精神

基金項目:本文系紹興市哲學社會科學規劃項目最终研究成果(145S004); 紹興文理學院校级科研 項目研究成果: 馬克思主義作為科學哲學在國外的歷史與現狀(2020SK001); 紹興文理學院科研啟 動項目成果:作為一種科學哲學的馬克思主義研究在國外。(20206011)。

\section{引言}

實現中華民族偉大復興是近代以來中華民族最偉大的夢想。“中國夢” 是對近代以來中國歷史的深刻 總結, 是對中華民族偉大復興的形象概括, 是新時期黨的思想理論建設的重大創新, 是馬克思主義哲學基礎 上科學與價值的統一, 標誌著黨對新時期社會主義建設的認識進一步深化, 是新時期指導社會主義實踐、構 建和諧社會的指導方針。為推進這一重大理論的研究, 本文擬從實踐智慧角度探討 “中國夢” 的科學内涵, 希冀為新時期社會主義理論建設提供一些建設性意見,並以此求教於學界同仁。

\section{一、實踐智慧概述}

實踐智慧是從實踐的角度探討智慧和人之間的關係。從歷史上看,最早提出這一思想的是蘇格拉底和 柏拉圖,而最明確論述這一概念的哲學家是亞里斯多德。在蘇格拉底和柏拉圖那裡, “德性就是理性 $(\log 0 \mathrm{~s})$, 實踐智慧指的是知識與德性的統一, 實踐智慧就是一種有德性的知識或有知識的德性。在《尼各 馬可倫理學》中, 亞里斯多德明確提出 “實踐智慧” 這一概念, 並區分了人類認識事物和表述真理的五種能 力, 他在肯定實踐智慧的本質是踐行的同時, 也指出了其不同於普遍性知識的特點。在亞里斯多德哪裡, 實 踐智慧和理論智慧同屬理智德性。其共同之處在於, 二者均可以在普遍性的層面運作, 關注實踐判糹的真 實性, 以及構建行動的普遍規則。其不同之處在於, 實踐智慧還可以在特殊性的層面運作, 將普遍規則應用 於生活的具體情景, 去確定正當的行動。實踐智慧表徵了那些知道怎樣生活得更好的人, 是一種走向善的 行動趨向, 具有技術傾向所缺乏的道德意識, 而且實踐智慧和道德品性是一種互惠關係, 後者保證了前者在 目的上的正當性。

此外, 亞里斯多德區分了純粹科學、技術或應用科學與實踐智慧的區別。一方面, 純粹科學研究的是不 可改變的東西,而實踐智慧研究的是可改變且能夠改變的事物; 純粹科學追求的是單純的真理,實踐智慧關 注的是人的具體生活,追求人類生活中最大的 “善”。另一方面,實踐智慧與技術或一般的應用科學在本質 上也有所不同。技術的本質是製作或生產,而實踐智慧的本質是踐行; 技術是工具或手段,其目的存在於製 作或生產之外, 實踐智慧的踐行本身就是目的, 它關心人類自身的價值和意義。“實踐智慧既不是科學, 也 不是技術。它之所以不是科學, 是因為踐行的領域是可以改變的; 它之所以不是技術, 是因為踐行和製作種 類不同。所以結論是, 實踐智慧是一種與正確計畫相聯熬並堅持正當行為的踐行能力, 而這種践行的物件 是那些對善或不善的事物。因為在製作時在自身之外尚有別的目的, 但踐行卻不會是這樣, 因為良好的踐 行本身就是目的。”(1)

綜上所述, 實踐智慧也就是實踐領域的智慧, 是那些對人類有益或有害的事情採取行動的真實的、伴隨 著理性的能力狀態, 它既不同於理論領域的理論智慧, 也不同於製作領域的技藝智慧。實踐智慧以意識的 
Asia-Pacific Journal of Humanities and Social Sciences

形式內化於人同時以技藝的形式外顯於實踐過程, 在目的上展現為 “理應做什麼” 的價值關懷, 在過程上突 顯為 “理應如何做” 的理性探求, 正是在解釋世界與改造世界的相互聯結中, 智慧被賦予實践的品性, 同時實 踐也擁有了智慧的內涵。

\section{二、“中國夢”的理論建構是理論理性與實踐理性的統一}

在現實的實踐之中, 實踐智慧首先體現人與世界的互動。一方面, 人以不同的方式認識世界,另一方面 也在不斷地改造世界,正是在解釋世界和改造世界的過程中, 完成了主體的建構, 化自在之物為為我之物。 在此, 解釋世界與 “是什麼” 相關聯, 內含了人對世界的經驗知識, 是一種理論理性的表達; 改變世界則內含 了“應當成為什麼”的價值關切, 主要是一種實踐理性的體現。相比之下, 在實踐智慧中, “是什麼” 的理論理 性與“應當做什麼”的實踐理性獲得了統一: 理論理性為實踐理性提供現實的根據,而實践理性則為理論理 性提供價值引導。與之相聯繫,認識世界與改造世界也獲得了讋證的統一,認識世界為改造世界提供理論 前提,而改造世界的歷史需要則為認識世界提供內在動力。簡言之, “以變革世界的實践關切接引對世界的 理論解釋, 以解釋世界的理論觀念範導對世界的實踐變革,構成了實践智慧的內在特點。”(2)

“中國夢”記錄著中華民族從飽受屈辱到贏得獨立解放的非凡歷史, 承載著為開創中國特色社會主義道 路艱辛探索的偉大歷程, 展現了中國特色社會主義前程似錦。“中國夢” 的提出是建立在對中國近代歷史發 展規律和社會主義建設經驗的科學總結之上,有著深刻的歷史淵源。中華民族曾經創造了令世界歎為觀止 的世界文明,但是鴉片戰爭之後, 中國逐漸走向衰落。“中華民族的偉大復興” 不僅是恢復中華民族曾經的 輝煌, 更是在歷史的基礎上不斷創新和取得新的更大的成就。復興是針對曾經的衰落而言的。正因為我們 有過往日的輝煌, 也有過曾經的屈辱, 所以才會有復興的宏願。正是在總結歷史發展規律的基礎上, 我們才 提出了復興的夢想, 對歷史的深刻總結是夢想提出的理論前提; 同樣, 為實現中華民族的偉大復興美好願望 也為我們更好的總結歷史、展望未來注人了新的活力。以實現中華民族偉大復興的改革實践接引對中國近 代歷史的深刻解讀, 以中國近現代史發展規律的理論總結范導偉大復興的實踐變革, 體現了理論理性與價 值理性的統一,體現了新一代党的領導人的實踐智慧。

\section{三、“中國夢”的價值關切是個體理性與整體理性的統一}

首先, 亞里斯多德指出, 實践智慧既體現於了解何物對自我是有益的, 同時也涉及“合乎邏輯的、真實的 能力形態”,並以此“為人的利益而行動”。 ${ }^{3}$ 同時,實踐智慧應該指向 “一種好的生活”, 並關注 “總體上的有 益生活”。 ${ }^{(4)}$ 在此, 合乎邏輯體現了實踐的理性品格,而“為人的利益而行動” 則內含了實踐的價值訴求, 它以 改造世界並使之合乎人的發展需要為目標, 體現了說明世界與改造世界的内在關聯。同時,基於存在的本 源價值, 亞里斯多德認為, 具有實践智慧的人更加善於考慮“總體上的有益”, 而不僅僅限於特定的利益。

習近平指出, 我們要時刻傾聽人民呼聲、回應人民期待, 使發展成果更多更公平惠及全體人民, 持續改 善民生, 打好復興之基,共築中國夢。從“貧窮不是社會主義”到“共同富裕”, 從“發展是硬道理”到“全面建 成小康社會”,幾十年來, 發展經濟、改善民生始終是黨和政府的重中之重,黨中央始終把“不斷實現好、維護 好、發展好最廣大人民的根本利益” 放在各項工作的首位, 將人民的利益作為各項工作的出發點和落腳點。 “中國夢” 的提出, 新一代黨的領導集體, 以中國最廣大人民的根本利益為行動原則, 以改善民生為宗旨, 將 全體人民的“有益生活”貫穿于全面建設小康社會的始終, 旨在使全國人民過上“一種好的生活”,實現全體 人民的共同富裕,既體現了實踐的理性品格,同時也內含了實践的價值訴求,是理性與價值的統一。

其次, 實踐智慧在價值目標上主要體現為成己與成物。成已是指個體的自我完成與群體的價值實現, 成物旨在化自在之物為為我之物。以成已與成物為內容的實踐智慧, 内含了 “應當做什麼” 的價值追求和 
“為何應當做”的價值追問的讋證統一。在不同的社會背景下, 實踐智慧的目標指向往往有所不同, 在社會 領域,主要是關注個體的完善與群體價值的實現。

“中國夢是民族的夢,也是每個中國人的夢” (5), 個人夢和國家夢有著内在的聯繫, 個人的奮鬥離不開國 家,個人夢的實現離不開國家夢的實現; 同時,國家夢的實現又有賴於每一個人把自己的聰明材質和創造力 最大程度的發揮出來,個人夢是國家夢的重要組成部分。“中國夢歸根到底是人民的夢, 必須緊緊依靠人 民,必須不斷為人民造福”。 同時, “生活在我們偉大祖國和偉大時代的中國人民,共同享有人生出彩的機 會, 共同享有夢想成真的機會, 共同享有同祖國和時代一起成長與進步的機會。” 在此, “中國夢” 既關注國 家的富強、民族的復興, 也注重個人的全面發展, 在成就祖國偉大夢想的同時也成就個人的夢想, 而且最終 目的就是為了實現個人的全面發展,體現了價值追求與價值追問的辨證統一。

\section{四、中國夢的路徑選擇是工具理性與價值理性的統一}

實踐的目的決定了實踐的方向和途徑,方向與價值取向相關聯,體現的是價值理性,而途徑則與方式方 法相關聯,更多的體現為一種工具理性層面的考慮。在實踐智慧中,二者呈現為彼此交融的形態,二者之間 的溝通過程同時也是根據目的選擇手段的過程。亞里斯多德說: “實踐智慧使我們選擇正確的手段。” “沒有 實踐智慧,選擇就不可能正確,正如沒有德性,選擇就不可能正確一樣。” ${ }^{8}$ 因此,我們可以說, 目的與手段的 溝通過程就是實踐智慧在思維過程中的實現過程。同時, 目的中的價值原則暗含了普遍性的内涵, 而手段 的具體運用則與特定的情境相關聯。實踐目的的實現無疑需要普遍性觀念的引導,但是, 由於實踐行為主 體所處的社會環境不同,實践的背景和境遇也是變動不居的。因此,如何實現普遍的原則規範與具體情境 的協調溝通, 是需要訴諸於實践智慧的。在實踐智慧中,一般原則的抽象性和教條化得以揚棄, 在特定的情 境中獲得具體的內涵與特定品格, 同時, 經驗的自發性和盲目性得以克服,在一般的原則下獲得自覺的品 格。如亞里斯多德所說: “實踐智慧不僅考慮普遍, 而且考慮特殊, 後者由經驗為人所熟知。” 里黑格爾也認 為, “為了能夠實現, 善還必須得到特殊化的規定。” ${ }^{10}$ 在此, 特殊化同樣藴含著普遍原則在具體情境中的現實 化問題。伽達默爾在論及實践知識時也提到實踐知識是 “針對具體情況的, 因此它必須把握 “情況” 的無限 多的變化”们可見,實踐智慧具有溝通一般原則與具體情境的內在特點。

實現“中國夢”必須堅持走中國特色社會主義道路。中國特色社會主義道路是中國共產黨人在總結革 命和建設經驗的基礎上,將馬克思主義基本原理與中國實際相結合而提出的發展戰略, 是由我國的具體國 情決定的。新時期,小康社會的全面建設,和諧社會的構建,有著巨大的發展機遇,但同時也面臨著巨大的 挑戰, 沒有現成的模式可用,也沒有可供參考的實踐經驗, 要實現中華民族的偉大復興, 只有結合中國自身 的具體國情, 走中國自己的道路。新一代黨的領導集體, 堅持走中國特色社會主義道路, 堅定理論自信、道 路自信、制度自信, 為實現中華民族偉大復興而努力奮鬥的實踐表明, “中國夢” 作為普遍觀念, 其抽象化得 以揚棄, 在中國特色社會主義道路中獲得了具體的内涵與特定品格; 同時, 在“中國夢” 的規範指引下,也使 得中國道路避免了自發性和盲目性。以中國夢為規範引導, 以中國道路做實踐路徑, 體現了新時期黨的決 策的實踐智慧。

\section{五、中國夢”的實踐主體是主體理性與交往理性的統一}

在談到實踐智慧的特點時, 亞里斯多德指出: “那些理性的形態都可能被遺忘, 而實踐智慧不可能被遺 忘。” ${ }^{11}$ 理性的形態與具體的知識經驗相聯繫,實踐智慧則表現為 “知的能力”,它形成于現實的實踐過程,同 時內在於實踐主體之中, 具體化為人的存在規定,制約和影響人的實踐過程。同時,實踐智慧呈現出綜合的 特點,包含有多方面的內容,首先就是與德性相關, 亞里斯多德曾經指出: “實踐智慧是一種德性。” ${ }^{13}$ 這裡的 
德性既有本體論的意藴也有價值論的內涵, 既可理解為與人同在的本體論規定, 也呈現出一種善的品格。

就實踐過程而言, 它需要主體之間觀念上的溝通與理解, 行動中的協調與配合。實踐目標的確認, 實踐 計畫的制定, 在實際行動之前都屬於觀念層面的形態, 與之相關的一致和共識也屬於觀念層面的溝通。要 實現這種溝通,既需要宣導者的引導與說服,也需要參與者的理解與接受,而這些都是以認識世界和變革世 界之間的關聯為前提,以實踐主體之間的溝通為基點。另一方面,在實踐過程之中,面對複雜多變的實踐環 境,如何採用恰當的方式方法以協調不同實踐主體的行動, 同樣離不開實践智慧。以溝通 “應當做什麼” 與 “應當如何做” 為內容, 它是協調實踐主體活動的內在依據。可見, 無論是觀念層面的理解與溝通, 還是行動 中的協調與配合,都內含了實踐智慧。

“實現中國夢必須凝聚中國力量”, 中國力量是各族人民大團結的力量, 是 13 億中華兒女的力量, 對中 國夢的實現具有根本性和決定性。中國夢是億萬人民的夢,需要全社會的共同參與,需要各階層的同心同 德。習近平指出, “中國夢” 歸根到底是人民的夢, 必須僅僅依靠人民來實現。為此, 黨中央指出 “要堅持黨 的領導、人民當家作主、依法治國有機統一, 堅持人民主體地位, 擴大人民民主” “要隨時傾聽人民呼聲、回 應人民期待,保證人民平等參與, 平等發展權利, 維護社會公平正義”, 同時“要鞏固和發展最廣泛的愛國統 一戰線, 加強民主黨派和無黨派人士的團結合作, 鞏固和發展平等團結互助和諧的社會主義民族關係…… 最大限度團結一切可以團結的力量”。回以上各種原則和指導方針顯示了黨在新時期的建設中始終把人民群 眾的利益放在首位, 體現了黨堅持人民群眾是歷史主體的唯物史觀, 同時, 為協調發展過程中的不同利益主 體之間關係而採取的各種發展戰略,實現了“做什麼” 與 “如何做” 的溝通,為協調各種利益關係提供了内在 依據。“中國夢”的提出為不同主體之間的觀念溝通提供了思想支撐, 同時保證了不同利益主體之間的協調 與配合,而這些都是在實踐智慧的指導之下做出的正確決策。

\section{結語}

綜上所述,以實現個人全面發展和構建和諧社會為指向的“中國夢”,是在總結中國歷史發展的基礎上 對中國未來社會發展的合理性追求, 是對當下中國社會情景的整體感知、辨別與頓悟, 是對中國精神的彰 顯, 融合了理論理性 (認識功能) 和實踐理性 (意志功能), 體現了認識世界與改造世界的統一。其中, 既包括 “做什麼” 的價值關切,也內含“如何做” 的理性判迦, 既關注“是什麼”理論追求,也注重 “怎樣做”的價值追 問。基於發展的理念 ““中國夢”既關注社會經濟的發展, 同時注重中國自身的特殊國情,將普遍的理論指引 與具體的情景分析相結合, 展現了獨特的方法論取向。同時, 作為德性與能力相統一的中國夢,始終以人的 存在與發展作為本體論前提, 內在於人並與人同在。可見, 中國夢的理論旨趣, 意在將價值取向、知識經驗、 行為方式和存在者融為一體, 最終形成為統一的觀念性形態並凝結于中國人心目中, 並通過特定的實踐方 式協調不同利益主體之間的行動,為實現中華民族的偉大復興提供思想基礎, 它具有實踐與智慧的雙重品 格,是實踐與智慧的統一。

\section{注釋}

(1)(3)(8)(12)(13) McKeon,R. ( 1941). The basic works of Aristotle. New York: Random

(2)楊國榮:論實踐智慧, 中國社會科學, 2012 年第 4 期, 頁 6 。

(5)6(7) 習近平:在第十二屆全國人民代表大會第一次會議上的講話, 人民日報, 2013-03-17。

(10) 黑格爾:《法哲學原理》, 商務印書館, 1961 年版, 頁 137 。

(11) 伽達默爾:《真理與方法》, 上卷, 商務印書館 1960 年版, 頁 26 。

(14) 習近平:在第十二屆全國人民代表大會第一次會議上的講話, 人民日報, 2013-03-17。 